\title{
Experimental study of gas-liquid flow local characteristics in rectangular microchannel
}

\author{
German Bartkus ${ }^{1,2, *}$ \\ ${ }^{1}$ SB RAS, Kutateladze Institute of Thermophysics, 630090 Ac. Lavrentieva ave. 1, Novosibirsk, \\ Russia \\ ${ }^{2}$ Novosibirsk State University, 630090 st. Pirogova 1, Novosibirsk, Russia
}

\begin{abstract}
Using high-speed video recording and the method of dual laser scanning the gas-liquid flow was investigated in a rectangular microchannel with an aspect ratio of 0.74 (cross section $269 \times 362 \mu \mathrm{m}$ ). The T-mixer was used at the channel's inlet for the two-phase flow formation. The peculiarity of this work is using a number of liquids (ethanol, distilled water, $40 \%$ aqueous ethanol) with different physical properties, including surface tension, viscosity, and density, with nitrogen. Experiments were carried out for the vertically upward and horizontal flow. Using laser scanning method the maps of flow patterns were obtained for all mixtures.
\end{abstract}

\section{Introduction}

Significant attention is paid now to investigations of gas-liquid and liquid-liquid flows in microchannels. This fact is connected with using of microchannels in high-intensity cooling systems, based on microchannel heat exchangers, in chemical reactors, and biological chips for rapid blood test [1]. This shows that study of local characteristics is urgent because these characteristics influence on the intensity of heat and mass exchange processes in various technological and natural processes [2-4]. The hydrodynamics of gas-liquid and liquid-liquid flows in microchannels was studied in a number of works in which the main flow patterns were defined, e.g. [3, 5, 6]. In paper [7] local characteristics of the flows (such as liquid distribution in microchannel) were investigated. These characteristics are used for creating heat and mass transfer models such as for example in [8,9].The present study aims at conducting the experiments of gas-liquid flow using liquids with different physical properties and generalizing flow pattern maps for vertical and horizontal flows.

\section{Experimental equipment and methods}

The experimental setup for studying the upward vertical and horizontal gas-liquid flow in a rectangular microchannel is shown in Fig. 1 (a). Nitrogen, which is fed from a highpressure tank (11) via the control valve (10) and gas flow controller (4) to the test section, is used as working gas. Water flows from the tank (7) with filter (filter rating $1 \mu \mathrm{m}$ ) through a fluid flow controller (3) and further into the T-shaped mixer at the inlet of the test section,

* Corresponding author: germanbartkus@,gmail.com 
i.e. microchannel $(2)$. Connectors $(8,9)$ allow removing the tank and pour liquid very rapidly. Gas and liquid flow controllers $(3,4)$ by Bronkhorst are powered by power supplies $(5,6)$ of the same company. Test section is a microchannel, assembled from glued glass and aluminum plates with length $\mathrm{L}=30 \mathrm{~cm}$. The hydraulic diameter is much smaller than the capillary constant. From the exit of test section, the gas-liquid mixture is moved to the liquid tank (1), where the gas escapes to the atmosphere.

The study of gas-liquid flow patterns was conducted using the method of dual laser scanning, see Fig. 1 (b). Two lasers $(12,13)$ are positioned so that the laser beams (15) illuminate one side of the rectangular channel. A lens (14) is used to change the diameter of the laser spot. The lasers are powered using voltage power source. The intensity of transmitted light is measured by photodiodes (16) arranged at the opposite side of the channel. The electric voltage from the photodiodes is analyzed using high-speed ADC and processed on the computer over the period from one to two minutes. This method is very useful for determining statistical characteristics of two-phase flow, e.g. [7]. Flow patterns are also registered using the high-speed camera Optronis CX600x2 (17). The first laser is located at a distance of $6 \mathrm{~cm}$ from the inlet, while camera - at $17.7 \mathrm{~cm}$ from the inlet, and second laser - at $22.4 \mathrm{~cm}$ for observing the stable gas-liquid flow. Physical properties of used liquids are shown in Table 1.

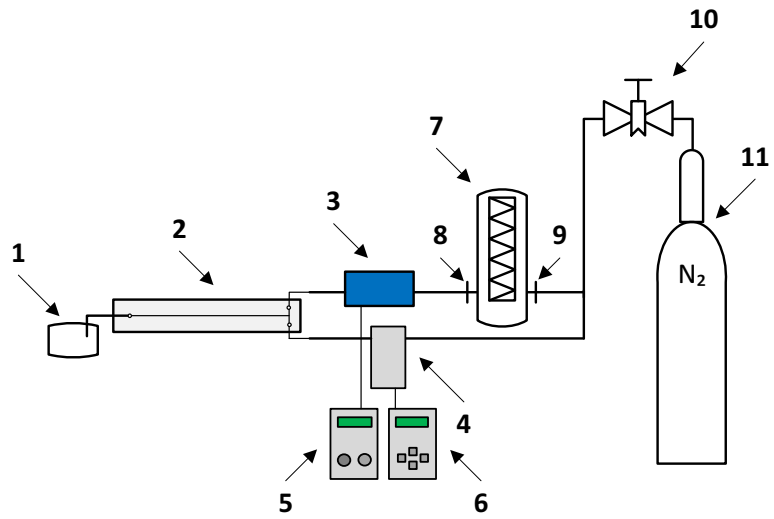

a

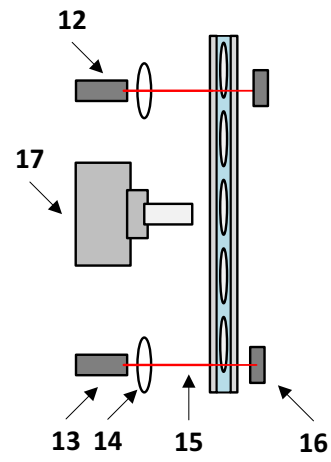

b

Fig. 1. Experimental setup (a), scheme of the dual laser scanning method (b).

Table 1. Properties of used liquids

\begin{tabular}{|c|c|c|c|}
\hline \multicolumn{4}{|c|}{ Physical properties } \\
\hline Liquid & $\begin{array}{c}\text { Density, } \boldsymbol{\rho} \\
{\left[\mathbf{k g} / \mathbf{m}^{\mathbf{3}}\right]}\end{array}$ & $\begin{array}{c}\text { Viscosity, } \\
\boldsymbol{\eta}[\mathbf{m P a} \cdot \mathbf{s}]\end{array}$ & Surface tension, $\boldsymbol{\sigma}[\mathbf{H} / \mathbf{m}]$ \\
\hline Distilled water & 998.2 & 1.004 & 0.073 \\
\hline Ethanol & 789 & 1.190 & 0.0223 \\
\hline $40 \%$ aqueous ethanol solution & 935.2 & 2.910 & 0.03 \\
\hline
\end{tabular}

\section{Two-phase gas-liquid flow in microchannels}

The high-speed video and laser scanning method show that the periodic flow with elongated gas bubbles (Taylor bubbles), the transition flow, and the annular flow are the main flow regimes in microchannels with the gap substantially less than the capillary constant. 


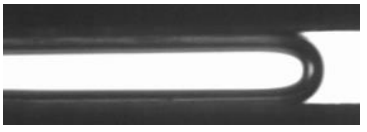

(a)

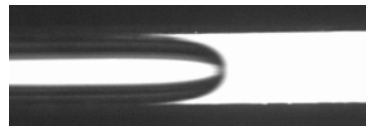

(b)

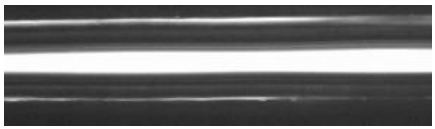

(c)

Fig. 2. Visualization of ethanol-nitrogen flow in horizontal microchannel $269 \times 362 \mu \mathrm{m}$ : a - photo of elongated bubble flow, $\mathrm{J}_{\mathrm{lig}}=0.066 \mathrm{~m} / \mathrm{s} \mathrm{J} \mathrm{gas}_{\mathrm{gas}}=0.072 \mathrm{~m} / \mathrm{s}, \mathrm{b}-$ transition flow, $\mathrm{J}_{\mathrm{lig}}=0.066 \mathrm{~m} / \mathrm{s} \mathrm{J}_{\mathrm{gas}}=1.14 \mathrm{~m} / \mathrm{s}$, $\mathrm{c}$ - annular flow, $\mathrm{J}_{\mathrm{lig}}=0.054 \mathrm{~m} / \mathrm{s} \mathrm{J}_{\mathrm{gas}}=3.82 \mathrm{~m} / \mathrm{s}$.

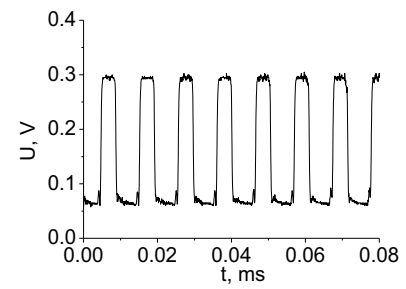

(a)

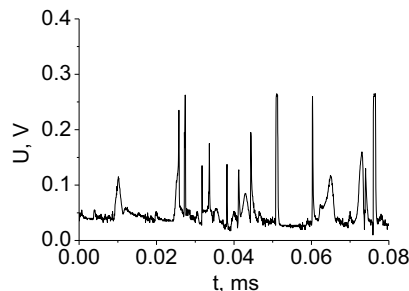

(b)

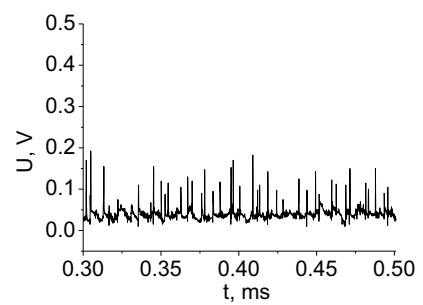

(c)

Fig. 3. Horizontal flow in microchannel of $269 \times 362 \mu \mathrm{m}$ (ethanol-nitrogen). The dynamics of voltage signal on the photodiode for elongated-bubble flow at superficial velocities of liquid and gas $\mathrm{J}_{\text {liq }}=0.072 \mathrm{~m} / \mathrm{s}, \mathrm{J}_{\text {gas }}=0.147 \mathrm{~m} / \mathrm{s}(\mathrm{a})$, transition flow $-\mathrm{J}_{\text {liq }}=0.072 \mathrm{~m} / \mathrm{s}, \mathrm{J}_{\text {gas }}=1.399 \mathrm{~m} / \mathrm{s}(\mathrm{b})$, annular flow $\mathrm{J}_{\mathrm{liq}}=0.036 \mathrm{~m} / \mathrm{s}, \mathrm{J}_{\mathrm{gas}}=3.62 \mathrm{~m} / \mathrm{s}(\mathrm{c})$.

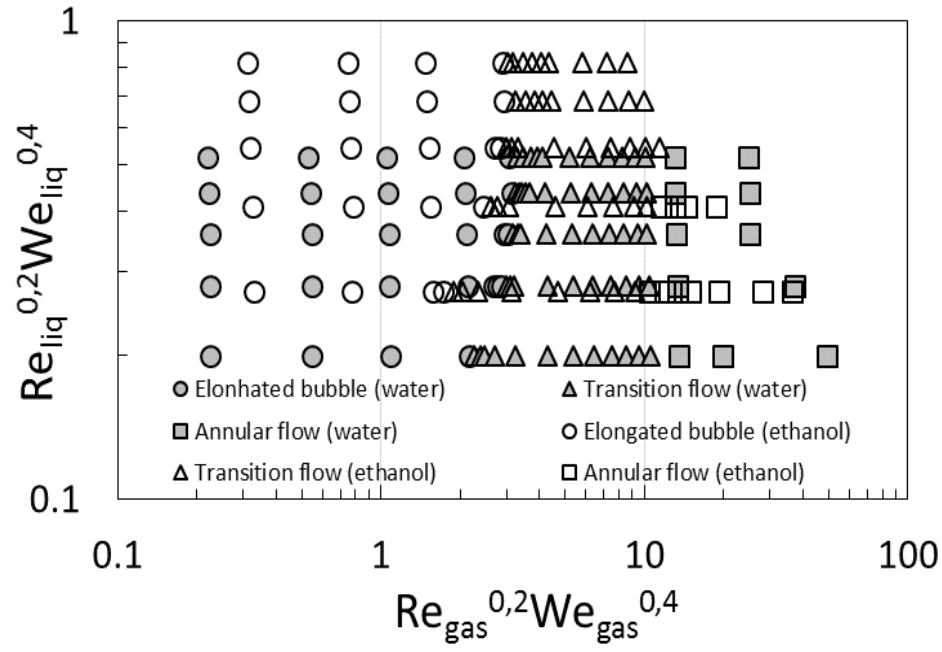

Fig. 4. Flow pattern maps for ethanol-nitrogen and water-nitrogen mixtures in a horizontal microchannel with hydraulic diameter $D_{h}=309 \mu \mathrm{m}$.

The photograph and voltage signal from photodiode for three regimes are presented in Figs. 2 and 3 for horizontal ethanol-nitrogen experiment in 269x362 $\mu \mathrm{m}$ microchannel.

\section{Flow pattern maps}

Flow pattern maps for ethanol-nitrogen and water-nitrogen flows in horizontal microchannel were constructed in the coordinates of the dimensionless complex $R e^{0.2} W e^{0.4}$ proposed by Waelchli [9], and representing the combination of Re and We numbers. Formulas for $\operatorname{Re}(1)$ and $W e(2)$ numbers are shown below: 


$$
\begin{array}{r}
\operatorname{Re}_{\text {liq,gas }}=\frac{J_{l i q, \text { gas }} \cdot D_{h}}{v_{\text {liq, gas }}} \\
W e_{\text {liq,gas }}=\frac{\Delta \rho \cdot J_{l i q, \text { gas }}{ }^{2} \cdot D_{h}}{\sigma} .
\end{array}
$$

The maps are presented in Fig. 4. Offered coordinates give a good generalization of the experimental data for boundaries of regimes for liquids with different properties.

\section{Conclusion}

We carried out the experiments, aimed at studying the influence of liquid physical properties (surface tension, viscosity, density) and the orientation of the microchannel in space (horizontal, vertical) on the flow regimes and the regions of their existence. Ethanol, distilled water, and $40 \%$ aqueous ethanol solution were used as the liquid phase, while nitrogen was taken as the gas phase. It was established that for the present microchannel with a hydraulic diameter substantially less than the capillary constant, three basic flow regimes are formed: flow with elongated gas bubbles, the transition, and annular flow. The effect of the different orientation of the microchannel (horizontal, vertical) on the boundaries of flow regimes is negligible that shows the dominance of capillary forces. Based on the visualization and laser scanning method, flow pattern maps were constructed for 2 types of mixtures using the dimensionless complex $R e^{0.2} W e^{0.4}$, proposed by Waelchli [9]. The dimensionless complex makes it possible to take into account the physical properties of the liquid and gives a good generalization of the experimental data.

This work was performed by a grant of the Russian Science Foundation (project No. 16-19-10519).

\section{References}

1. V. Kuznetsov, J. Phys.: Conf. Ser. 754, 032012 (2016)

2. V. Kuznetsov, S. Dimov, P. Houghton, 1st Int. Conf. on Microchannels and Minichannels. ASME, 683 (2003)

3. V. Kuznetsov, I. Kozulin, A. Shamirzaev, J. Phys.: Conf. Ser. 395, 012093 (2012)

4. V. Kuznetsov, A. Shamirzaev, I. Kozulin, Heat Tran. Eng. 34, 235 (2013)

5. A. Kovalev, A. Yagodnitsyna, A. Bilsky, Chem. Eng. J. 303, 547 (2016)

6. G. Bartkus, V. Kuznetsov, MATEC Web of Conferences 84, 00005 (2016)

7. I. Kozulin, V. Kuznetsov, J. Appl. Mech. Tech. Phys. 52, 956 (2011)

8. V. Kuznetsov, A. Shamirzaev, Heat Tran. Eng. 37, 1105 (2016)

9. S. Waelchli, P. Rudolf von Rohr, Int. J. Multiphase Flow 32, 791 (2006) 